\title{
ETHICAL RESPONSIBILITY DIRECTIVES AIMED AT BIG SOCIAL DATA RESEARCH
}

\author{
Charmaine du Plessis \\ Professor, Department of Communication Science, University of South Africa, Pretoria, South Africa
}

\begin{abstract}
Despite the ongoing debate about ethics about big data and big social data, there are still no universal directives how to ethically deal with largescale datasets. Even big social data that is anonymous and seemingly harmless may have ethical implications and impacts that have not been previously anticipated. Hence, this paper explores the idea that, in the absence of universally agreed-upon ethical principles for big social data studies, researchers must adopt an ethical maturity focal point for such research projects. It is argued that researchers, who deal with big social data, must be ethically responsible and apply autonomous moral reasoning during all phases of the research process. To support the arguments, the study was conducted in two phases. The concept of ethical maturity was first extended to big social data research, after which some ethical directives are proposed, based on an inductive analysis of documents on the topic of ethics of big data and social data. The findings indicate that being ethically responsible could instill a greater appreciation of the current and new big social data context in researchers to justify ethical decision-making while becoming more aware of the manipulated reality of big social datasets.
\end{abstract}

\section{KEYWORDS}

Big Social Data, Inductive Analysis, Fourth Industrial Revolution, Ethical Maturity, Research Ethics, Ethical Responsibility

\section{INTRODUCTION}

This paper aims to contribute to the ongoing debate on ethics about big data with a focus on big social data research. The volume of big social data generated in the Fourth Industrial Revolution (4IR) concerns areas of business, society and even existence, and remains a controversial topic. Big social data is the direct result of the 4IR and the way such data is harvested and used is inherently ethics unfriendly. Concerns about ethics regarding big data and big social data have focused predominantly on aspects such as privacy, identity, ownership and reputation from scholars' and practitioners' different perspectives and epistemologies (Zook et al., 2017; Richterich, 2018).

Consequently, this paper explores the idea that, while it is difficult to apply ethics to big social data, researchers must, apart from being knowledgeable about ethics, also become ethically responsible. This means that researchers, who deal with big social data, must adopt an ethical maturity approach, anchored in autonomous moral reasoning during all phases of the research process.

The first aim of this paper is to explore how the concept of ethical maturity can be extended to big social data research. Second, the paper addresses the question of how being ethically mature can direct big social data research in the (4IR) by proposing some ethical directives. Framed by Klaus Schwab, founder and executive chairman of the World Economic Forum in 2016, the 4IR entails the fusion of technologies by blending the online and offline world, providing researchers with research opportunities previously unimaginable (Schwab, 2016). The 4IR brings a "Zetta flood of zettabyte data", which is the equivalent of a billion terabytes (Barnett, 2016). Specifically, the 4IR has made harvesting of data for research more widespread, because of ease of access and availability. For example, innovative technologies such as the internet of things (IoT), robotics and artificial intelligence (AI), among other things, generate large volumes of big social data (Floridi, 2014; Van den Hoven, 2017).

The past few years have seen the rapid development of new technologies during the 4IR, slowly dissolving the barriers between humans and technologies, while providing ample research opportunities to not only shape government, but also business and the quality of humans' connected lives (Marcus, 2015). As 
a direct result of the 4IR, large volumes of data have become readily available in the public domain, which can be routinely collected and analysed for purposes of research, without asking for informed consent (Herschel \& Moir, 2017). Ethics of big social data research is increasingly a vital concern, but universally agreed upon guidelines on how to ethically deal with large social media datasets for research are still lacking, mainly due to the level of difficulty to conform with ethical theory (Richterich, 2018; Herschel \& Moir, 2017; Zook et al., 2017). One of the most significant current discussions in big social data research is what ethics entails when using big data for purposes of research or strategic decision-making (Zook et al., 2017).

Furthermore, concerns about misusing big social data are rising, including issues about human rights, global governance and property. For example, organisations collect consumers' data, without their knowledge or consent, to not only monetise but also to provide tailor-made services to current and potential new customers (Marcus, 2015).

The paper is structured as follows: The concept of big social data is first explained, followed by an explanation of the concept of ethical maturity. Thereafter big social data is extended to ethical maturity followed by an explanation of the research method, findings, discussion and conclusion.

\section{BIG SOCIAL DATA}

Although the concept of big data is well-documented in the literature, there is still no universal agreement about its nature and is best understood as an umbrella concept that refers to emerging technologies, but also includes the infrastructure, practices, networks and even politics surrounding their use. Big data is thus networked data in such volumes that data cannot be processed by conventional computer or database systems (Kitchin \& McArdle, 2016; Schwab, 2016). Big data has characteristics such as volume (being an enormous quantity), velocity (harvested in real-time), variety (having different formats) and veracity (contains uncertainty and errors), but also has value (can provide much insight and be repurposed) and variability (the meaning of the data can change in accordance with the context) (Kitchin \& McArdle, 2016).

Social media data is an application of big data and is defined as "generated from technology-mediated social interactions and actions in the digital realm, and which can be collected and analyzed to model social interactions and behavior" (Olshannikova et al., 2017).

There is no single template of how to apply ethics in social media research since studies differ. This means that ethical problems are context-dependent and subject to different interpretations by researchers. Researchers can harvest big social data via social media sites, devices, machines and endless other applications, which are often unstructured, spread around and noisy (Olshannikova et al., 2017; Zook et al., 2017). However, human reality is not the same as a decade ago, as we only observe online information in accordance with how we personalise devices, the internet and social media, based on our interests and connections (Just \& Latzer, 2017). Since all these new technological devices of the 4IR help to construct reality and create new responsibilities for researchers, when harvesting and using big social data, it is important to acknowledge how this affects ethical theory.

It is thus argued in this paper that in the absence of some clear guidelines, researchers are compelled to think differently about how to harvest and use big social data in the 4IR. Not only are researchers faced with more complicated and larger social media datasets, but ethical considerations are also becoming more urgent since it is not practical to obtain informed consent. This urgency is thus embedded in how to address the sensitive aspects of human behaviour and interactions, without informed consent. Research agendas, using big social data, now include a network that connects humans and communities with technologies with the potential to cause harm, since most data represents or impacts humans (Metcalf \& Crawford, 2016; Zook et al., 2017). Importantly, ethics around big social data deals with less visible concepts such as information privacy and data discrimination, which might impact an individual or a larger grouping of people (Metcalf \& Crawford, 2016). It is hence argued that the concept of ethical maturity could direct researchers in how to become ethically responsible when dealing with large social media datasets.

\section{ETHICAL MATURITY}

The concept of ethical maturity is widely applied in health sciences and the helping professions (see, for example, Caroll \& Shaw, 2013; Caroll, 2014; Lategan \& Van Zyl, 2017), and reflected on in organisational studies (Wickham \& O' Donohue, 2012; Steven \& Godkin, 2017). Also referred to as moral or human 
maturity, there are diverse views about what ethical maturity entails and, consequently, there is no universally agreed-upon definition. One of the most prominent scholars that has written about ethical maturity, Caroll (2011, p.12), defines ethical maturity as "the reflective, rational and emotional capacity to decide actions are right and wrong, or good and better; the resilience and courage to implement those decisions; being accountable for ethical decisions made." On the other hand, Wickham and O' Donohue's (2012) support Kohlberg's (1984) theory of moral development who defines ethical maturity as "the highest level of moral development at which an individual is capable of autonomous moral reasoning using abstract universal principles, such as human rights and justice, to determine what is ethical." Vivian-Burne and Hunt's (2014, p.5) definition focuses more on the complexity of ethics, namely "the increasing capacity to embrace ethical complexity and deal with appropriate respect to all parties involved in a situation."

Although there are different views about what ethical maturity entails, as evident in these definitions, collectively, scholars agree that ethical maturity leads to better ethical decision-making when facing an ethical dilemma that enables one to not only take but also to sustain the right practice (Caroll, 2011; Caroll \& Shaw, 2013; Wickham \& O' Donohue, 2012).

\subsection{The Concept of Ethical Maturity Extended to Big Social Data Research}

For the empirical part of the study, the perspectives of Wickham \& O' Donohue (2012) and Caroll (2011) were adopted as a theoretical point of departure, to position ethical maturity within a big social data research context. These scholars' work on ethical maturity has attracted attention and is widely cited. Firstly, Caroll (2011) argues that when it comes to ethical maturity, developing ethical sensitivity and vigilance to alert researchers of the presence of ethical dilemmas are important. This alertness will assist in researchers' understanding of why particular ethical decisions were taken. Similarly, Wickham and O' Donohue (2012) argue that being socially intelligent is essential to not only understand but also to interpret different social situations and interactions. Therefore, researchers, who deal with big social data, must be able to interpret and understand social situations, interactions, roles and norms embedded in the data, based on the purpose of the data. This could help researchers to become sensitive to the potential ethical dilemma of harvesting and using big social data. Secondly, for Caroll (2011), it is important to be able to rationalise all ethical decisions and then to implement them. To be able to do this, it is important to think individually, relationally and systematically. Researchers must endeavour to become more experienced in ethical decision-making. In this regard Wickham and O' Donohue (2012) refer to cognitive intelligence, namely being able to interpret information rationally and to adapt to the environment. This means that the researcher must access, process and interpret big social data in a focused, methodical and logical manner while being cognizant of potential ethical issues. Thirdly, Caroll (2011) puts forward that it is essential to not only learn from the ethical decision that was taken but also to be able to justify the decision. Equally important is that ethical decision-making must be aligned to researchers' ethical principles and values. For Wickham and O' Donohue (2012), emotional intelligence is important, since, having this ability not only regulates one's emotions but also allows us to sense and respond to others' emotions. Thus, for the researcher, this means that they must continuously learn from ethical experiences and regulate any bias towards the big social dataset while staying respectful because of the human-related aspects behind human interactions. Table 1 below summarises how the ethical maturity concept can be extended to big social data research.

Table 1 . The concept of ethical maturity extended to big social data research

\begin{tabular}{ll}
\hline Ethical maturity aspects & $\begin{array}{l}\text { Proposed meaning within the context of big } \\
\text { social data research }\end{array}$ \\
\hline Social intelligence: ethical sensitivity, vigilance & $\begin{array}{l}\text { Understanding of social situations, interactions, } \\
\text { roles and morals embedded in the data, the privacy } \\
\text { of individuals }\end{array}$ \\
Cognitive intelligence: justification, implementation & $\begin{array}{l}\text { Access, process and interpret social media data in a } \\
\text { focused, methodical and logical manner }\end{array}$ \\
Emotional intelligence: Learning, outcomes & $\begin{array}{l}\text { Learn from the experience and regulate any bias } \\
\text { about the data and stay respectful, adopt a human- } \\
\text { centred approach }\end{array}$ \\
\hline
\end{tabular}

Sources: Wickham \& O’Donohue (2012); Carroll (2011). 


\section{METHOD}

This quality study adopted an interpretivist worldview and was done in two different phases. Firstly, the concept of ethical maturity was extended to big social data research, based on the frameworks of two well-cited scholars. Secondly, an inductive approach was adopted for a qualitative textual analysis by considering the ethical aspects in table 1 as well as their proposed meaning within the context of big social data research. For the analysis, a purposive sample of a corpus of 51 electronic reports on big data and big social data ethics, in the public domain, was used and searched for with keywords using search engines and Google scholar (see van Dijck 2010). These reports, with an average length of 30 pages, and consisting of 997475 words and 35486 unique word forms, were compiled by industry experts, regulating bodies in the private and public sectors, and universities. The unit of analysis was thus social artefacts. To be included in the study, the reports had to make proposals of how to ethically deal with big data or big social data research in the 4IR.

Coding and theme development were guided by existing ideas and concepts, as reflected in table 1 (see Braun \& Clarke, 2013). In addition to Braun and Clarke's (2013) guidelines, the eight-step planning process of a quality study, as proposed by O’Leary (2014), was also considered.

Following an iterative data collection approach, data saturation was attained, in other words, no new data and, thus, no new themes became available with further reports (Fusch \& Ness, 2015). Well-adopted criteria for inclusion and exclusion of documents for analysis, such as authenticity, credibility, representativeness and meaning of the reports, were applied (Bowen, 2011; Tight, 2019).

The documents were subjected to a systematic review, as proposed by Tight (2019) and Braun and Clarke (2013). Reading and understanding of the documents were also facilitated by robust qualitative data analysis software such as NVivo for Windows and Voyant Tools (a web-based application for text visualisation and analysis). A reflexive inductive thematic analysis followed, keeping in mind the ethical issues and their proposed meaning within the context of big social data research, as depicted in table 1 . The researcher thus imposed this structure on the data to analyse it (Braun \& Clarke, 2013).

The data analysis meets the criterion of trustworthiness, because a well-known systematic and exhaustive process, based on the frameworks of well-cited scholars, was followed (Tight, 2019).

\section{FINDINGS}

Three themes emerged from the inductive thematic analysis and which can be explained as follows.

\subsection{Theme 1: Appreciation of the Current and New Context of the Big Social Dataset}

Theme 1 deals with a greater appreciation of and reflection on the current and new context of the dataset, before harvesting and using it for studies. Appreciation of the current and new context of the data refers to researchers being vigilant and ethically sensitive about human-related social situations, conversations, roles and norms that cannot be separated from the data (Carroll, 2011; Wickham \& O' Donohue, 2012). This appreciation is important because researchers must understand that, without exception, all big social datasets pose an ethical dilemma, since human participants and communities' conversations are naturally embedded in the data (Metcalf \& Crawford, 2016). Because ethics about big social data is inherently complex and difficult to apply (Herschel \& Moir, 2017), researchers must become sensitive to the current and new context of the big dataset by being more aware of the social context of the data. For example, the analysis reveals that researchers must not be distracted by how public the data is, but rather understand where the data originates from and how the data may cause harm when used in another context. In this regard boyd and Crawford (2012) argue that researchers cannot justify their research as being ethical just because the data is public, but that research ethics for the dataset must still be evaluated. Also, an understanding of how the handling of the data in another context adheres to researchers' values becomes essential. This means that researchers must acknowledge the purpose of the original data and first reflect on how the data will fit the new context of the research study, without changing the intended meaning thereof and without causing any harm. Also, the new 
context in which the data will be used should ideally contribute to new knowledge about a phenomenon and benefit society. Ethical sensitivity and vigilance will ensure that a researcher not only interprets the data appropriately but also becomes more aware of the human elements embedded in the data and the importance of protecting the privacy of human participants. Greater awareness could thus ensure proper usage of big social data and prevent potential harm to human participants (Zook et al., 2017). Hence at the start of a research study, the following questions are important: Where does the data come from? Is lawful to obtain the data? Will the data fit into the new context of the study? What harm can the data inflict upon humans when used in a study? What new knowledge will the data generate that will improve society?

\subsection{Theme 2: Justification of the Reasons for Ethical Decision-Making}

Theme 2 addresses the justification for the implementation of ethical decisions about harvesting big social data for use in a new context. This means that the researcher must not only access and process but also interpret, big social data methodically and logically while being aware of potential harm to human participants. Also, the researcher must be able to adapt to address potential ethical issues detected during the research process. Justification for ethical decision-making, before the start of the project and during the entire research process, is essential (Carroll, 2011; Wickham \& O' Donohue, 2012), which is also revealed by the analysis in terms of ethics being a conscious consideration whenever a new research project commences. This means that ethical issues can emerge at every new development of a study which researchers must be aware of. For example, studies of a sensitive nature or of interest to national security, could affect the personal security and integrity of the researcher (Van Baalen, 2018). Furthermore, how human rights are affected by harvesting and using big data could substantiate and justify all ethical decisions and actions. It is important to always assess the potential impact of big social data on human participants (see Beninger et al., 2014). The researcher must also display ethical resilience during the implementation of the research project, guided by logical decision-making. Hence, the following questions are important: How is ethics applicable to all the phases of the study? Are there any ethical issues that have emerged not previously being aware of? Are there any risks involved for the researcher when using the data? How can the researcher become more experienced in ethical decision-making? How can decisions about the ethical implications of using this data be justified to others?

\subsection{Theme 3: Awareness of the Tailored Reality of the Big Social Dataset}

Theme 3 addresses awareness of how to regulate bias about the human-related information, embedded in the big data, which does not necessarily reflect the entire truth (Carroll, 2011; Wickham \& O' Donohue, 2012). This means that researchers must adopt a human-centred approach, they must always learn from the experience and stay respectful throughout the entire research process. Knowledge and cognizance about matters such as algorithm bias, data discrimination and the non-neutrality of technology, which may alter human reality, are imperative.

The analysis reveals that issues such as algorithm bias, data discrimination and living in a "filter bubble", because of personalised searchers on the internet, are all realities that hide some information from researchers; thereby, limiting their views about the world and the data (see Just \& Latzer, 2016; Philbeck et al., 2018). Also, big social datasets may have algorithm errors and algorithms may also change the initial purpose of the data. Big social data can also be a tool of inclusion and exclusion, because of the digital divide and exclusion of human participants, who do not have access to the internet and social media. In addition, the engineers behind the creation of algorithms have their ideas about the purpose of the data, which means that technology is not neutral. Thus, when dealing with big social data, researchers must always be aware that the data may not reflect the entire truth; it only provides a snapshot or idea of the truth. Thus, staying respectful during the entire research process is not only essential but must also be guided by shared human values and universal principles such as human rights and justice. Hence, the following questions are important: Does this data reflect human reality as it is? Is this data based on a personalised search? Which algorithm errors could potentially be embedded in the data? Which humans were potentially excluded in the data? How can any bias about the dataset be reported and overcome? 


\section{DISCUSSION}

The contribution of this paper is twofold. Firstly, in the absence of a universal agreement on this topic, the study opens opportunities for further debate and studies by extending the concept of ethical maturity to big social data research. Secondly, the findings of this study will help researchers with practical ethical directives, anchored in autonomous moral reasoning during all phases of the research process. Because it advocates for more reflection on the potential harm to human participants, these principles can act as a moral compass to guide researchers with decision-making when accessing, analysing, using and sharing big social data. The current study thus contributes to our knowledge by addressing both theoretical and practical issues pertaining to ethics around big social data research. Big social data is inherently not ethics friendly when it comes to the ideas put forward in ethics theory (Herschel \& Moir, 2017) and generated from non-neutral technologies (Philbeck et al., 2018). How to address ethics when it comes to the sensitivity surrounding human behaviour and interactions embedded in the data, obtained without informed consent, have not only been a controversial topic, but also a grey area in big social data research (Richterich, 2018; Zook et al., 2017). It is therefore vital for researchers to not only become more knowledgeable about concerns about ethics surrounding big social data research (Marcus, 2015), but also to be ethically responsible when making ethical decisions concerning big social data, as proposed in this paper. By asking questions about ethical issues around the big social datasets, researchers have a greater awareness of the current and new context of big social data, can provide justifications for ethical decisions and be attentive to the fact that a big social dataset only provides a snapshot or idea of the reality of the phenomenon under investigation. By being vigilant, ethically sensitive, flexible, resilient, and by adopting a human-centred approach and staying respectful, researchers adhere to shared human values and universal principles such as human rights and justice. Moreover, ethics must be a conscious consideration whenever a new big social data research project commences. Table 2, below, depicts the proposed ethical directives for when researchers approach big social data research.

Table 2. Proposed ethical directives for moral reasoning when approaching big social data research

\begin{tabular}{ll}
\hline Directive & Proposed questions for studies using big social data \\
\hline $\begin{array}{l}\text { Directive 1: Appreciation } \\
\text { of the current and new context of the bi } \begin{array}{l}\text { Where does the data come from? Will the data fit into the new context of the } \\
\text { social } \\
\text { data }\end{array}\end{array}$ \\
$\begin{array}{l}\text { humans when used in a study? What new knowledge will the data generate that } \\
\text { will improve society? } \\
\text { of the reasons for ethical decision- } \\
\text { making }\end{array}$ & $\begin{array}{l}\text { How is ethics applicable to all the phases of the study? Are there any ethical } \\
\text { issues that have emerged not previously being aware of? Are there any risks } \\
\text { involved for the researcher when using the data? How can the researcher become } \\
\text { more experienced in ethical decision-making? How can decisions about the } \\
\text { ethical implications of using this data be justified to others? }\end{array}$ \\
$\begin{array}{l}\text { Directive 3: Awareness of the tailored } \\
\text { reality of the big social dataset }\end{array}$ & $\begin{array}{l}\text { Does this data reflect human reality as it is? Is this data based on a personalised } \\
\text { search? Which algorithm errors could potentially be embedded in the data? } \\
\text { Which humans were potentially excluded in the data? How can any bias about } \\
\text { the dataset be reported and overcome? }\end{array}$ \\
\hline
\end{tabular}

\section{CONCLUSION}

The paper concludes by arguing that the ethical directives proposed in this study could act as a contribution to the debate about ethics about big social data and be further developed through productive discussion. These directives are thus not proposed as final but must continue to evolve as part of lifelong learning. The complex nature of big social data continues to hamper ethical decision-making, while ethical concerns about big social data research, in the absence of informed consent, are well-documented. No doubt, harvesting and using big social data, when humans did not give their consent to use their data or are not aware of the research, have ethical implications in all spheres of life. The volume of big social data is also still mounting as new technologies become available, while researchers will continue to harvest and use large volumes of 
data for research. It is acknowledged that ethics in big social data research is highly specified and that there is no one-size-fits-all approach. Also, the results of this study can only be generalised to the sample of this study while documents could have been omitted during searches. The insights gained from the analysis, nevertheless, provide another angle to not only address but also to expand on ethics about big social data research. Despite the study's limitations, the results are valuable considering the idea that ethical maturity could be a novel way in which to deal with sensitivities around human activities embedded in large volumes of social data. When researchers are aware of the potential harm to human participants when making decisions about big social data, their actions could become more aligned with shared human values and human rights. This is very much the key component in future attempts to further develop the concept of ethical maturity through different methodologies within the context of big social data. It will be important for future studies to develop and add to the ethical directives proposed in this study. Equally important is to rethink the nature, importance and practice of research integrity when it comes to large scale social media datasets.

\section{REFERENCES}

Barnett, T. (2016). The Zettabyte Era Officially Begins (How Much is That?). Cisco Blogs. https://blogs.cisco.com/sp/the-zettabyte-era-officially-begins-how-much-is-that.

Bowen, GA. (2009). Document analysis as a qualitative research method. Qualitative Research, 9(2), $27-40$.

Beninger, K., Fry, A., Jago, N., Lepps., H., Nass., L., \& Silvester, H. (2014). Research using Social Media Users' Views. NatCen Social Research, 1-40.

boyd, D., \& Crawford, K. (2012). Critical questions for big data. Information, Communication and Society, 15(5), 662-679.

Braun, V., \& Clarke, V. (2013). Successful qualitative research: A practical guide for beginners. SAGE.

Carroll, M. (2011). Ethical maturity: Compasses for life and work decisions-Part I. Psychotherapy in Australia, 17(3), $12-23$.

Carroll, M., \& Shaw, E. (2013). Ethical Maturity in the Helping Professions. Jessica Kingsley Publishers.

Carroll, M. (2014). Effective Supervision for the Helping Professions. $2^{\text {nd }}$ edition. SAGE.

Herschel, R., \& Miori, VM. (2017). Ethics \& Big Data. Technology in Society, 49, 31 - 36.

Fusch, P. I., \& Ness, L.R. (2015). Are we there yet? Data saturation in qualitative research. The Qualitative Report, 20(9), 1408-1416.

Floridi, L. (2014). The Fourth Revolution: How the Infosphere is reshaping human reality. Oxford University Press.

Just, N., \& Latzer, M. (2017). Governance by Algorithms: Reality Construction by Algorithmic Selection on the Internet. Culture \& Society, 39(2), 238-258.

Kitchin, R., \& McArdle, G. (2016). What makes Big Data, Big Data? Exploring the ontological characteristics of 26 datasets. Big Data \& Society, January-June, 1-10.

Kohlberg, L. (1984). The Psychology of Moral Development: Nature and Validity of Moral Stages. Harper.

Lategan, L.O.K., \& Van Zyl, G J. (Eds). (2017). Healthcare ethics: For healthcare practitioners. Sun Media.

Marcus, A. (2015). Data and the fourth industrial revolution. World Economic Forum. https://www.weforum.org/agenda/2015/12/data-and-the-fourth-industrial-revolution/.

Metcalf, J., \& Crawford, K. (2016). Where are human subjects in Big Data research? The emerging ethics divide. Big Data \& Society, January-June, 1-14.

O’Leary, Z. (2014). The Essential Guide to Doing Your Research Project. 2nd ed. SAGE.

Olshannikova, E., Olsson, T., Huhtamaki, J., \& Karkkainen, H. (2017). Conceptualizing Big Social Data. Journal of Big Data, 4(3), Springer Open, https://doi.org/10.1186/s40537-017-0063-x.

Philbeck, T, Davi, N., \& Larsen, A.E. (2018). Values, Ethics and Innovation Rethinking Technological Development in the Fourth Industrial Revolution. World Economic Forum.

Richterich, A. (2018). The Big Data Agenda: Data Ethics and Critical Data Studies in Critical Digital and Social Media Studies Series. University of Westminster Press, $1-14$.

Steven W., McCrary, P.E., \& Godkin, L. (2017). An Organizational Construction Ethics Maturity Model: The Integration of Process and Normative Values [Paper Presentation]. 53rd ASC Annual International Conference Proceeding, Seattle, WA (pp. 317 - 327), Associated Schools of Construction.

Tight, M. (2019). Documentary Research in the Social Sciences. SAGE. 
Van Baalen, S. (2018). 'Google wants to know your location': The ethical challenges of fieldwork in the digital age. Research Ethics, 14(4), 1-17.

Van den Hoven, J. (2017). Ethics for the Digital Age: Where are the Moral Specs? [Paper Presentation] In H. Werthner \& F. van Harmelen (Eds). Proceedings of the 11th European Computer Science Summit: Informatics in the Future, Vienna (pp. 65-76), Springer.

Van Dijk, J. (2010). Search engines and the production of academic knowledge. International Journal of Cultural Studies, 13(6), 574-592.

Vivian-Byrne, K.l., \& Hunt J. (2014). Ethical Decision-Making - social metaphors towards ethical action. Journal of Systemic Therapies, 33(1), $1-15$.

Wickham, M., \& O' Donohue, W. (2012). Developing an ethical organization: exploring the role of ethical intelligence. Organization Development Journal, 30(2), 9 - 29.

Zook, M., Barocas, S., boyd, D., Crawford, K., Keller, E. \& Gangadharan, S. P., et al. (2017). Ten simple rules for responsible big data research. PLoS Comput Biol, 13(3), e1005399 https://doi.org/10.1371/journal.pcbi.1005399. 